\title{
MANIFESTAÇÃO CLÍNICO-PATOLÓGICA DE INFECÇÃO NATURAL PELO VÍRUS RESPIRATÓRIO SINCICIAL BOVINO (BRSV) EM BOVINOS DE CRIAÇÃO EXTENSIVA NO RIO GRANDE DO SUL, BRASIL ${ }^{1}$
}

\author{
David Driemeier $^{2}$, Marcos José Pereira Gomes 3 , Valéria Moojen ${ }^{3}$, Clarice Weiss Arns ${ }^{4}$, \\ Guilherme Vogg ${ }^{5}$, Luciano Kessler ${ }^{5}$ e Ubirajara Maciel da Costa ${ }^{6}$
}

\begin{abstract}
Driemeier D., Gomes M.J.P, Moojen V., Arns C.W., Vogg G., Kessler L. \& Costa U.M. 1997. [Clinic-pathological aspects in the natural infection of Bovine Respiratory Syncytial Virus (BRVS) in extensive management of cattle in Rio Grande do Sul, Brazil.] Manifestaçào clínico-patológica de infecção natural pelo vírus respitarório sincicial bovino (BRVS) em bovinos de criação extensiva no Rio Grande do Sul, Brazil. Pesquisa Veterinária Brasileira 17(2):77-81. Depto Patologia e Clínica Veterinária, Faculdade de Veterinária, Universidade Federal do Rio Grande do Sul, Caixa Postal 15094, Porto Alegre RS 91540-000, Brazil.

The clinical aspects as well as the pathology, microbiology and serology of a natural Bovine Respiratory Syncytial (BRSV) infection of bovine in a herd of 600 beef cattle kept under extensive management in the State of Rio Grande do Sul, Brazil, are described. Clinically two animals had chronic cough and severe dyspnea when forced to mild physical exercise. These two animals were euthanatized and post-morten examination was performed. The macroscopic changes were of pulmonary origin, such as disseminated alveolar emphysema, focal atelectasis and marked interlobular septal thickening. The fluorescent antibody test on lung cryostat sections was positive to BRSV for both animals, and it was negative to PI-3 virus, BVDV and BHV. The BRSV was isolated from the lung of one of the animals on MDBK, and was also identified by fluorescent antibody test. No association with Chlamydia psittaci was found by ELISA performed on lung tissues.

The histopathology showed syncytial cells, chronic emphysema, peribronchiolar muscle layer hypertrophy and squamous metaplasia of bronchial and bronchiolar epithelia. The serology to detect antibodies to BRSV resulted in $79 \%$ of positives from the first specimen collection. In this group of young animals some of them had a cough. The second samples collected 6 months later were from animals of different age groups resulting in 17.3\% of positives. This is the first report on clinical BRSV infection in Brazil.
\end{abstract}

INDEX TERMS: BRSV, bovine, extensive management, virology, serology, pathology, Respiratory Complex.

RESUMO.- São descritas as manifestações clínicas, patológicas, microbiológicos e sorológicos da enfermidade natural causada pelo Vírus Respiratório Sincicial Bovino (BRSV) em uma criação extensiva de bovinos de corte no Rio Grande do

\footnotetext{
${ }^{1}$ Aceito para publicação em 4 de junho de 1997.

2 Depto Patologia e Clínica Veterinária, Faculdade de Veterinária, Universidade Federal do Rio Grande do Sul (UFRGS), C.P. 15094, Porto Alegre, RS 91540-000; bolsista do CNPq (301076/93-6).

${ }^{3}$ Depto Patologia e Clínica Veterinária, Fac. Vet., UFRGS.

${ }^{4}$ Depto Microbiologia e Imunologia, Unicamp, C.P. 6109, Campinas, SP 13081-970.

${ }^{5}$ Mestrando do Curso de Pós-Graduação em Ciências Veterinárias, Fac. Vet., UFRGS.

${ }^{6}$ Acadêmico de Medicina Veterinária, Fac. Vet., UFRGS.
}

Sul. Clinicamente havia tosse crônica e dispnéia intensa frente a exercícios físicos mínimos em dois animais. Os dois foram sacrificados e necropsiados. As alterações macroscópicas eram pulmonares com enfisema alveolar disseminado, focos de atelectasia e espessamento dos septos interlobulares. A imunofluorescência para BRSV em corte de pulmão congelado foi positiva em ambos os casos, sendo negativa para Parainfluenza-3 (PI-3), Diarréia Vírica Bovina (BVDV) e Rinotraqueíte Infecciosa Bovina (BHV). Foi isolado BRSV em cultivo celular de MDBK a partir de um dos animais necropsiados. Nenhuma associação foi detectada através de ELISA para deteç̧ão de antígeno LPS gênero específico de Chlamydia psittaci no tecido pulmonar.

O exame histopatológico evidenciou células sinciciais, enfisema crônico, hipertrofia da camada muscular peribronquiolar e metaplasia escamosa do epitélio bronqui- 
al e bronquiolar. O exame sorológico para BRSV evidenciou $79 \%$ de soropositivos em uma primeira amostragem na qual havia animais jovens e alguns com tosse. $O$ segundo exame sorológico 6 meses após, proveniente de animais de diferentes faixas etárias, resultou em $17,3 \%$ de soropositivos. Este é o primeiro relato de doença causada por BRSV no Brasil.

TERMOS DE INDEXAÇÃO: BRSV, bovinos , criação extensiva, virologia, sorologia, patologia, Complexo respiratório.

\section{INTRODUÇÃO}

O Vírus Respiratório Sincicial Bovino (BRSV) foi identificado pela primeira vez em 1967 na Suíça por Paccaud \& Jacquier (1970) e no Japão (Inaba et al. 1970). A incriminação deste vírus como causador de enfermidades era duvidosa e a reprodução experimental da infecção produziu sintomatologia discreta em bovinos e ovinos (Jacobs \& Edington 1975, Lehmkuhl \& Cutlip 1979). Surtos de BRSV com infecção bacteriana secundária por Pasteurella multocida, Streptococcus pneumoniae e Mycoplasma bovis foram descritos em terneiros estabulados (Pirie et al. 1981, Van der Ingh et al. 1982). Este vírus é um dos agentes envolvidos no Complexo Respiratório Bovino responsável por grandes perdas econômicas principalmente em animais com menos de 1 ano de idade (Dungworth 1993). As alterações macroscópicas são de consolidação antero-ventral dos pulmões, com atelectasia e enfisema nos lóbulos caudais (Van der Ing et al. 1982). Histologicamente caracteriza-se pela presença de células sinciciais. Inclusões eosinófilas intracitoplasmáticas podem ser vistas dependendo principalmente da fase da infecção (Bryson et al. 1983). Embora em menor quantidade, a presença de células sinciciais pode também ocorrer na infecção pelo PI-3 (Dungworth 1993). A sintomatologia respiratória não é específica e inúmeros agentes podem estar envolvidos, tanto isolados como em associação (Bryson et al. 1979, Radostits et al. 1994).

No Brasil, o vírus foi detectado pela primeira vez por Gonçalves et al. (1993) através de imunofluorescência em corte de tecido congelado, e isolado a partir de pulmões de terneiros obtidos em frigorífico no Rio Grande do Sul (RS). Campalans \& Arns (1995) isolaram uma amostra de BRSV coletada de secreção nasotraqueal de bezerros com sintomas respiratórios procedentes do Rio Grande do Sul. Através de inoculações sucessivas em cultura de célula MDBK (MadinDarby Bovine Kidney) a qual foi denominada BRSV-25-BR.

$O$ presente trabalho visa descrever um surto de BRSV em bovinos de corte em regime extensivo sem associação com nenhum dos outros agentes secundários estudados e sem a consolidação pulmonar antero-ventral característica da associação com outros agentes que têm como porta de entrada a via aerógena.

\section{MATERIAL E MÉTODOS}

O surto de doença respiratória foi observado num rebanho de bovinos de corte com diferentes faixas etárias, cruzas de AberdeenAngus, totalizando 600 animais no município de Cachoeira do Sul,
RS. Através de atendimentos clínicos dois animais mais afetados foram examinados clinicamente, sacrificados e necropsiados, o primeiro em novembro 1995 e o segundo em janeiro de 1996. Amostras de tecidos foram coletadas para exames bacteriológicos, virológicos e histopatológicos. Foram efetuadas duas coletas de sangue para exames sorológicos. A primeira, realizada em fevereiro de 1996, totalizou 19 amostras de um lote de bovinos, com idade entre 12 e 18 meses, onde observava-se tosse quando estes animais eram recolhidos na mangueira. As amostras de soro foram analisadas através do teste de ELISA indireto em microplacas impregnadas com antígeno viral (BRSV-25-BR) realizado no Laboratório de Virologia da Unicamp, segundo metodologia de Grand et al. (1987). A segunda coleta foi realizada com 6 meses de intervalo em 75 animais de diferentes faixas etárias sem sinais clínicos de alterações respiratórias. Estas amostras foram analisadas, no mesmo Laboratório, através do teste de soroneutralização com 100 DICT50/ $\mathrm{ml}$ da amostra viral BRSV-25-BR isolada no Brasil.

O material para exame bacteriológico, de amostras de pulmão segundo a técnica de Carter \& Cole (1990) não identificou agentes bacterianos associados com a enfermidade respiratória. Amostras de pulmão foram submetidas ao teste de ELISA, utilizando anticorpo monoclonal para detecção do antígeno gênero-específico do LPS7 de Chlamydia, conforme a técnica de Eb \& Orfila (1988). Material para exame virológico constou de tecidos resfriados imediatamente após a necropsia. Realizou-se a imunofluorescência indireta para BRSV com anticorpos monoclonais8 em corte de pulmão congelado. $O$ teste de imunofluorescência indireta com anticorpos monoclonais também foi realizado para a detecção do BVDV, e imunofluorescência direta com anticorpos policlonais para os vírus PI-3 e BHV. Fragmentos de pulmão, obtidos dos dois animais, foram processados para inoculação em cultivo celular de MDBK adaptada ao soro equino (ATTCC CCL-22).

Fragmentos de tecidos para exame histopatológico foram fixados em formol tamponado a $10 \%$, incluídos em parafina e cortados a 3$5 \mu \mathrm{m}$ em micrótomo rotativo e corados com hematoxilina-eosina (HE) e pelo ácido fosfotúngstico de Mallory (Prophet et al. 1992).

\section{RESULTADOS}

Sinais clínicos

Observou-se tosse nos animais quando eram recolhidos em bretes de contenção, principalmente nos animais recém

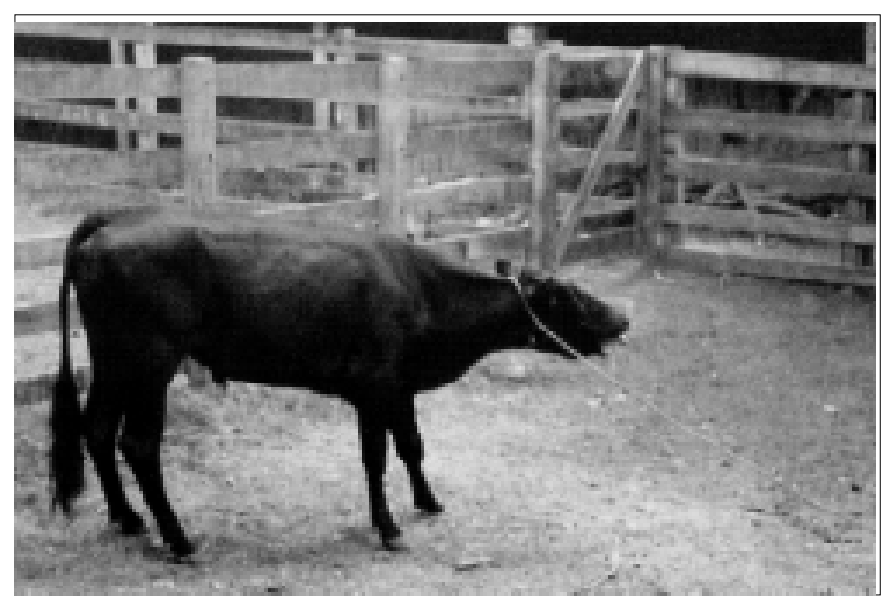

Fig. 1. Bovino de 4 anos, com tosse e regular estado de nutrição, do qual foi isolado BRSV. 
desmamados. Os dois animais sacrificados tinham idade de 4 anos e apresentavam regular estado de nutrição, porém ganho de peso marcadamente inferior aos outros animais da mesma faixa etária. A pelagem destes animais evidenciava pouco brilho. Observou-se tosse frequente (Fig. 1) e dispnéia intensa após exercícios físicos mínimos. Ao exame clínico dos dois animais mais afetados notou-se aumento da área pulmonar com visível afundamento da musculatura intercostal e estertores pulmonares intensos na auscultação. A temperatura corporal medida em um deles estava normal.

\section{Alterações anatomopatológicas}

Os principais achados macroscópicos na necropsia eram enfisema alveolar disseminado com focos de atelectasia dando um aspecto ondulado claro irregular na superfície da pleura visceral (Fig. 2). Enfisema intersticial era visto em pequenas áreas e pouco evidente. Havia espessamento marcado dos septos interlobulares. Pequenas franjas conjuntivas evidenciavam-se nos bordos do pulmão e que davam um aspecto fos- co a estas porções. O coração apresentava marcada hipertrofia do miocárdio do ventrículo direito em ambos os casos.

\section{Alterações histopatológicas}

O exame histopatológico evidenciou células sinciciais em grande quantidade localizadas principalmente nos bordos dos lóbulos pulmonares, presentes nos alvéolos, broquíolos e por vezes em vasos linfáticos (Fig. 3). Não foram observadas inclusões intracitoplasmáticas. As células sinciciais apresentavam número variável de núcleos dispostos centralmente. Era possível observarem-se áreas com formação inicial destas células em alguns alvéolos através da visualização de células com aspecto de macrófagos formando agrupados (Fig. 4). A presença de enfisema alveolar crônico com bordos de septos alveolares rompidos em forma de clava ( Fig. 5), por vezes intercalada com áreas de atelectasia, hipertrofia da camada muscular peribronquiolar e focos de metaplasia escamosa do epitélio bronquial e bronquiolar, estava bem evidente. Alterações inflamatórias eram moderadas e principalmente

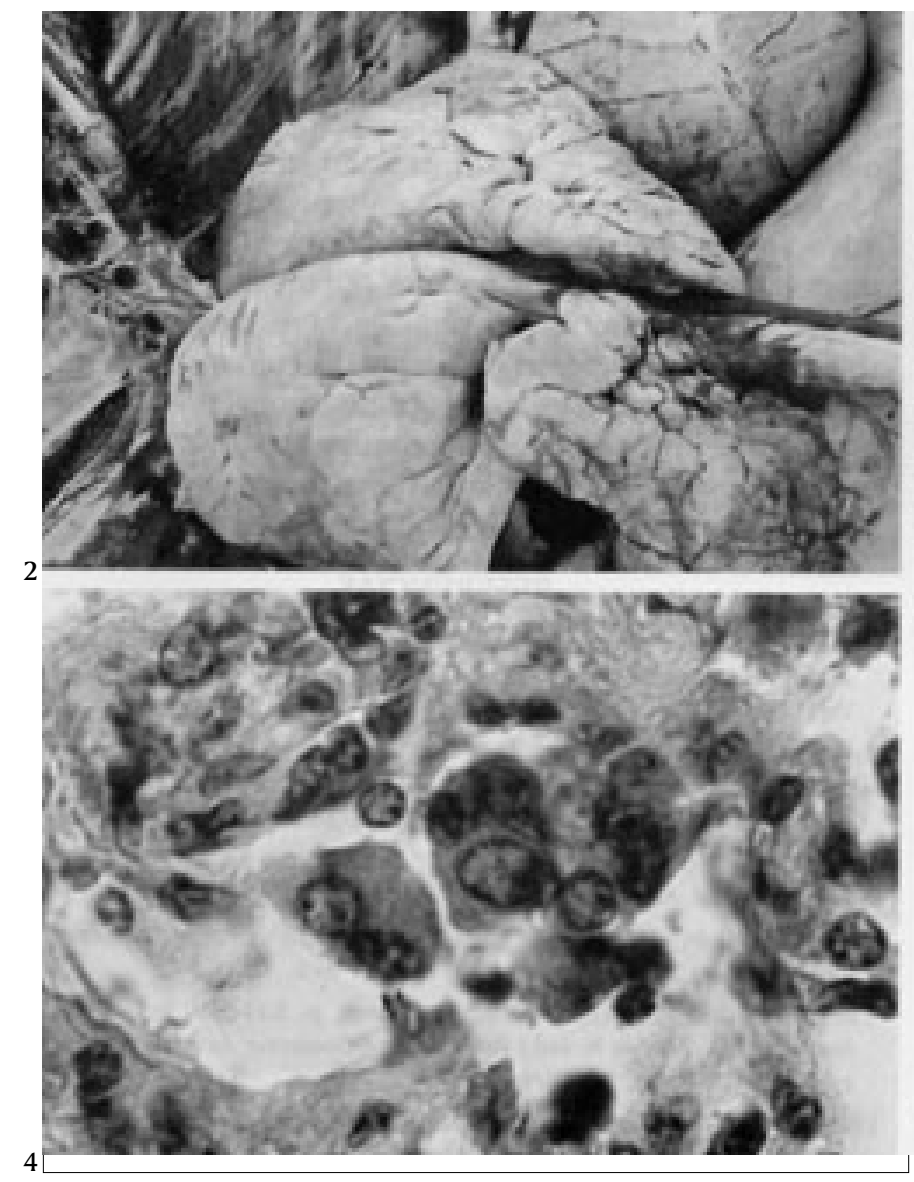

Fig. 2. Acentuado enfisema alveolar disseminado com pequenos focos de atelectasia dando um aspecto irregular à superfície externa do pulmão.

Fig. 4. Formação inicial de células sinciciais no interior de um alvéolo pulmonar. HE, obj. 100.

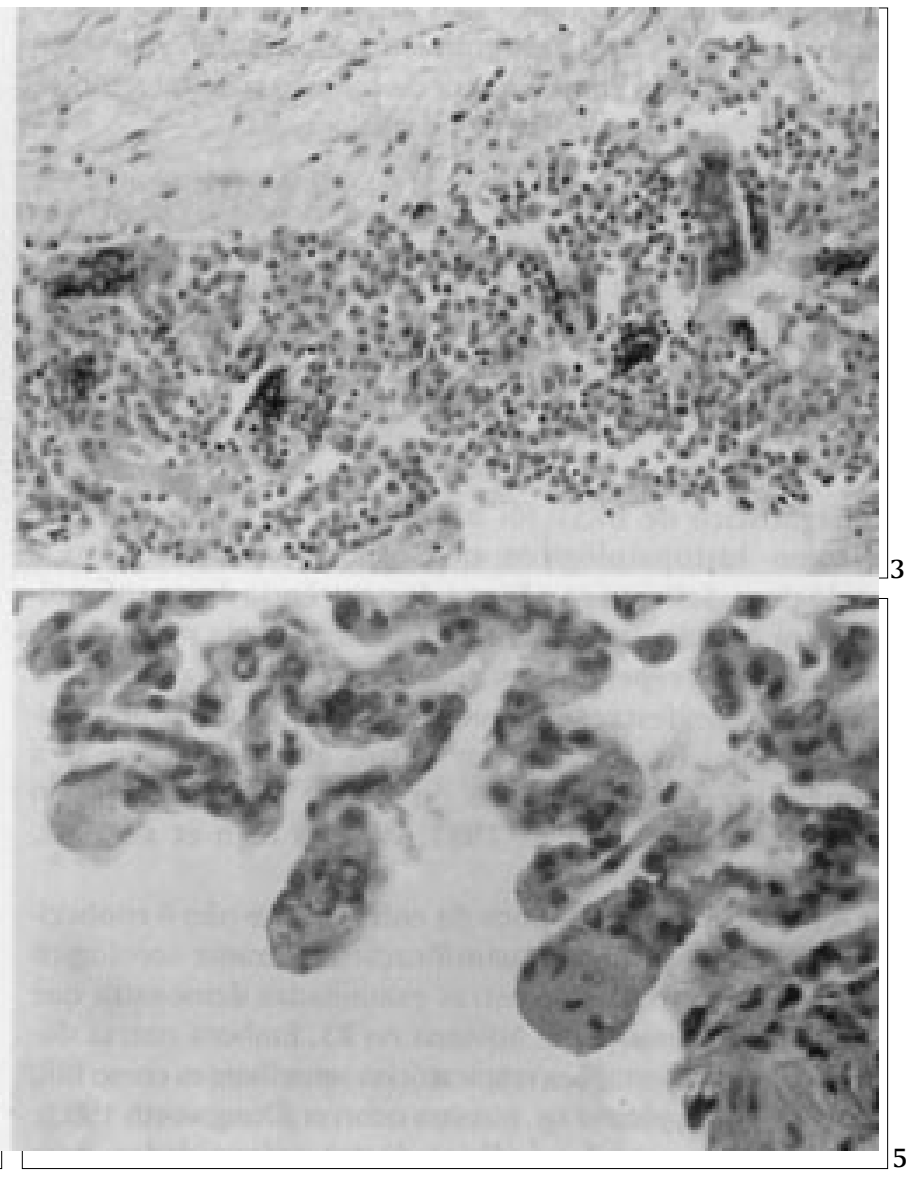

Fig. 3. Infiltração inflamatória de neutrófilos e macrófagos em um bronquíolo, com presença de grande quantidade de células sinciciais. HE, obj. 10.

Fig. 5. Bordas em clava dos alvéolos rompidos em consequência do enfisema alveolar crônico. HE, obj. 10. 
mononuclear com áreas focais de infiltração por eosinófilos. Os folículos linfóides peribronquiais estavam aumentados de volume. Alguns alvéolos apresentavam conteúdo róseo que foi positivo para fibrina na coloração do ácido fosfotúngstico de Mallory.

\section{Resultados virológicos}

A imunofluorescência em cortes de pulmão congelados feitos com materiais dos dois animais foi positiva para o BRSV, sendo negativa para os demais vírus pesquisados (BVDV, PI-3 e BHV). De um bovino necropsiado, foi isolado BRSV através do cultivo celular em MDBK, onde houve o aparecimento do efeito citopático compatível com BRSV, caracterizado pela formação de sincícios, arredondamento e morte celular em período de 3 a 4 dias da primeira inoculação; foram feitas duas passagens em MDBK. A imunofluorescência realizada nestes cultivos também foi positiva para BRSV, sendo negativo o seu controle que constou das mesmas células não inoculadas.

\section{Resultados bacteriológicos}

O exame bacteriológico não identificou agentes bacterianos associados com a enfermidade respiratória. Pelo teste de ELISA realizado com amostra de pulmão não detectou-se antígeno gênero específico LPS de Chlamydia.

\section{Resultados sorológicos}

Das 19 amostras da primeira coleta de sangue, $15(79 \%)$ foram positivas. Das 75 amostras de soro obtidas na segunda coleta, $13(17,3 \%)$ apresentaram resultados positivos através do teste de soroneutralização.

\section{DISCUSSÃO}

O diagnóstico de BRSV foi baseado nos achados clínicos, anátomo- histopatológicos, nos exames microbiológicos e sorológicos. Salienta-se a forma de ocorrência desta enfermidade em criação extensiva com sintomatologia respiratória crônica e com repercussões sistêmicas em dois animais. As principais manifestações clínicas da enfermidade com prejuízos econômicos descritas por outros autores referem-se a animais jovens estabulados ou recém introduzidos em confinamento (Pirie et al. 1981, Van der Ingh et al. 1982, Dungworth 1993).

A importância econômica da enfermidade não é conhecida no Brasil e de difícil quantificação. $O$ exame sorológico positivo em parte das amostras examinadas demonstra que o BRSV está presente em bovinos no RS. Embora outras doenças com manifestações respiratórias semelhantes como IBR, BVD, PI-3 e Mycoplasma sp. possam ocorrer (Dungworth 1993), não foram encontrados indícios destas enfermidades, nem mesmo uma associação entre elas e a infecção pelo BRSV nas amostras de tecidos examinadas. Chlamydia spp. e diversas espécies de Mycoplasma, dentre estas principalmente Mycoplasma bovis e M. dyspar, são citados como causadores de pneumonia enzoótica em terneiros, associados ou não com BRSV bem como outros agentes virais (Radostits et al. 1994).
Este fato justifica os exames efetuados nos casos de necropsia deste surto do qual não foi detectada a presença de Chlamydia, e, embora não tenha sido pesquisado Mycoplasma, não observaram-se alterações histopatológicas compatíveis com as citadas por Mycoplasma sp. (Dungworth 1993). A recuperação após a manifestação dos sinais clínicos quando ocorre, é observada entre 3 a 7 dias após o início dos sinais clínicos (Radostits et al. 1994). As manifestações clínicas observadas nos dois animais sacrificados eram crônicas e a sintomatologia existente demonstrava sequelas de uma insuficiência respiratória prolongada.

Os achados macroscópicos e histopatológicos também revelaram um quadro de insuficiência respiratória crônica. A ausência de inclusões intracitoplasmáticas nas células sinciciais do presente estudo pode ser devido ao fato de que as manifestações eram crônicas. Bryson et al. (1983) encontraram com frequência inclusões intracitoplasmáticas em animais do $5^{\circ}$ ao $8^{\circ}$ dia após a inoculação. Em surtos da enfermidade as inclusões podem ser vistas ocasionalmente (Dungworth 1993).

Em infecções por BRSV há também uma resposta imunomediada e possivelmente foi responsável por grande parte das lesões encontradas deste surto. Stewart \& Gershwin (1989) comprovaram a existência de correlação entre os sinais clínicos de BRSV e a concentração de IgE em lavados pulmonares. A presença do vírus e seu efeito citopático não são os únicos responsáveis pelo enfisema havendo também ativação do sistema de complemento e degranulação de mastócitos em animais infectados (Kimman et al. 1989). As manifestações crônicas de insuficiência respiratória característica sem envolvimento de agentes bacterianos secundários demonstram que esta doença pode ter importância na produtividade dos animais em criações extensivas. $O$ presente trabalho refere-se à primeira descrição das manifestações clínicas da infecção pelo BRSV no Brasil.

\section{REFERÊNCIAS}

Bryson D.G., McNulty M.S., Logan E.F. \& Cush P.F. 1983. Respiratory syncytial virus pneumonia in young calves. Clinical and pathologic findings. Am. J. Vet. Res. 44:1648-1655.

Bryson D.G., McFerran J.B., Ball H.L, \& Neill S.D. 1979. Observations on outbreaks of respiratory disease in calves associated with parainfluenza type 3 virus and respiratory syncytial virus infection. Vet Rec. 104:45-49.

Campalans J.B. \& Arns C.W. 1995. Isolation of Bovine Respiratory Syncytial Virus in Brazil. Anais $5^{\circ}$ Virológica 95, Ribeirão Preto, SP, B-34.

Carter C.R \& Cole J.R. 1990. Diagnostic Procedures in Veterinary Bacteriology and Mycology. 5th ed. Academic Press, New York. 620p.

Dungworth D.L. 1993.The respiratory system, p. 539-699. In: Jubb K.V.F., Kennedy P.C., Palmer N. (ed.) Pathology of Domestic Animals. Vol. 2. 4th ed. Academic Press, San Diego.

Eb F. \& Orfila J. 1988. Rapid direct immunological procedures. Proc. European Society for Chlamydia Research. Almqvist \& Wiksell International, Bolonha, Italy, p. 223-226.

Gonçalves I.P.D., Simanke A.T., Jost H.C., Hötzel I., Dal Soglio A. \& Moojen V. 1993. Detection of bovine respiratory syncytial virus in calves of Rio Grande do Sul, Brazil. Ciência Rural, Santa Maria, 23(3):389-390.

Grand M., Baxter-Jones C. \& Wilding G.P. 1987. An enzime-linked immunosorbent assay for the serodiagnosis of turkey rhinotracheitis infection. Vet. Rec. 21:279-280. 
Inaba Y., Tonaka I., Omori T. \& Matumoto M. 1970. Isolation of bovine respiratory syncytial virus. Japan J. Exp. Med. 40:473-474.

Jacobs J.W., \& Edington N. 1975. Experimental infection of calves with respiratory syncytial virus. Res. Vet. Sci. 18:299-306.

Kimman, T.H., Terpstra, G.K., Daha, M.R. \& Westenbrik F.1989. Pathogenesis of naturally acquired bovine respiratory syncytial virus infection in calves: Evidence for the involvement of complement and mast cell mediators. Am. J. Vet. Res. 50:694-700.

Lehmkuhl H.D \& Cutlip R.C. 1979. Experimental respiratory syncytial virus infection in feeder-age lambs. Am. J. Vet. Res. 40:1729-1730.

Paccaud M.F \& Jacquier C. 1970. A respiratory syncytial virus of bovine origin. Arch. Gesamte Virusforschung 30: 327-342,

Pirie H.M., Petrie L., Pringle C.R., Allan E.M. \& Kennedy G.J. 1981. Acute fatal pneumonia in calves due to respiratory syncytial virus. Vet. Rec. 108:411416,

Prophet E..B., Mills B., Arrington J.B. \& Sobin L.H. 1992. Laboratory Methods in Histotechnology. Armed Forces Institut of Pathology, Washington D.C. $278 \mathrm{p}$.

Radostits O.M., Blood D.C. \& Gay C.C. 1994. Veterinary Medicine. 8th ed. Baillère Tindall, London. 1763p.

Stewart R S \& Gershwin, L.J. 1989. Role of IgE in the pathogenesis of bovine respiratory syncytial virus in sequencial infections in vaccinated and nonvaccinated calves. Am. J. Vet. Res. 50:349-354

Van der Ingh T.S.G.A.M., Verhoeff J. \& Van Nieuwstadt A.P.K.M.I., 1982. Clinical and pathological observations on spontaneous bovine respiratory syncytial infections in calves. Res. Vet. Sci 33: 152-158 